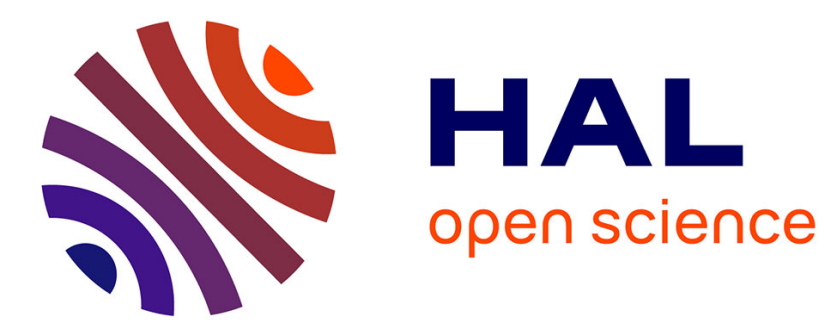

\title{
Multivariate analysis of within-tree factors accounting for the variation of peach fruit quality
}

\author{
Michel M. Génard, M. Bruchou
}

\section{To cite this version:}

Michel M. Génard, M. Bruchou. Multivariate analysis of within-tree factors accounting for the variation of peach fruit quality. Scientia Horticulturae, 1992, 52, pp.37-51. hal-02701661

\section{HAL Id: hal-02701661 \\ https://hal.inrae.fr/hal-02701661}

Submitted on 1 Jun 2020

HAL is a multi-disciplinary open access archive for the deposit and dissemination of scientific research documents, whether they are published or not. The documents may come from teaching and research institutions in France or abroad, or from public or private research centers.
L'archive ouverte pluridisciplinaire HAL, est destinée au dépôt et à la diffusion de documents scientifiques de niveau recherche, publiés ou non, émanant des établissements d'enseignement et de recherche français ou étrangers, des laboratoires publics ou privés. 


\title{
Multivariate analysis of within-tree factors accounting for the variation of peach fruit quality
}

\author{
M. Génard ${ }^{\mathrm{a}}$ and C. Bruchou ${ }^{\mathrm{b}}$ \\ ${ }^{a}$ Station d'Agronomie, INRA, Domaine Saint-Paul, 84143 Montfavet, France \\ ${ }^{b}$ Laboratoire de Biométrie, INRA, Domaine Saint-Paul, 84143 Montfavet, France
}

(Accepted 29 April 1992)

\begin{abstract}
Génard, M. and Bruchou, C., 1992. Multivariate analysis of within-tree factors accounting for the variation of peach fruit quality. Scientia Hortic., 52: 37-51.

The colour, firmness and flavour of 101 peach fruit from the south side of the tree were related to the characteristics of fruit-bearing shoots using a multivariate approach. The variability of quality was high between fruit. Fruit from the upper parts of the tree were more purple, less orange-red, less firm, had a higher sucrose content, a lower citric acid content and a higher $\mathrm{pH}$ than fruit from the lower parts. Fruit well exposed during the day had a purple skin, whereas less exposed fruit were more orange-red and had higher luminance $\left(L^{*}\right)$ and chrominance $\left(a^{*}, b^{*}\right)$. Fruit exposed to light essentially in the afternoon were more purple, less yellow and orange and more firm, had a higher citric acid content, lower sucrose and malic acid contents than fruit exposed to light in the morning. Colour variables were weakly correlated to the total leaf area. Fruit borne by thick shoots with high total leaf area, high leaf area per fruit late in season and a high yield were sweet and had high malic acid content. Sour fruit were linked with high total leaf area and high leaf area per fruit early in season. A semantic model for quality elaboration is proposed.
\end{abstract}

Keywords: fruit; multivariate analysis; Prunus persica; quality

Abbreviations: $\mathrm{Meq}=$ milliequivalent; $\mathrm{PCA}=$ principal component analysis; $\mathrm{PCAIV}=$ principal component analysis with instrumental variables.

\section{INTRODUCTION}

Fruit producers must produce high-grade fruit to satisfy consumers (good flavour, colour and texture) and marketers (fruit resistant to mechanical damage). Moreover, the variation in fruit quality must be as little as possible. However, with current practices, fruit quality varies considerably within the tree and improved horticultural practices are needed. This requires knowledge of the causes of fruit quality variability within the tree.

Correspondence to: M. Génard, Station d'Agronomie, INRA, Domaine Saint-Paul, 84143 Montfavet, France. 
Chalmers (1986) has suggested that fruit growth can change according to the position within the tree independently of environmental influences. This would be caused by hormonal signals produced by the apical buds, the leaves and the roots. The same hypothesis can be valid for fruit quality, since several components of fruit quality are correlated with fruit growth (Génard et al., 1991). Among other factors having an effect upon fruit quality, the leaf area (Weinberger, 1931; Facteau et al., 1983) and the light exposure (Marini et al., 1991) have been especially studied. The amount of leaves and light affects photosynthesis and determines the amount of carbohydrates available for fruit growth and quality. The light also directly affects fruit quality attributes, such as colour (Erez and Flore, 1986). Other factors such as the characteristics of fruit-bearing shoots (shoot diameter, length, etc.), used by fruit growers as criteria for pruning, probably also control fruit nutrition and quality.

The complexity of the concept of quality and the diversity of factors affecting fruit within the tree, make it necessary to analyse the variation of fruit quality through many attributes. Moreover, these attributes are "usually highly intercorrelated since biological systems, being complex and highly integrated, contain a great number of interacting components which are interrelated" (Broschat, 1979). The use of multivariate analyses is particularly well-adapted to this type of situation (Broschat, 1979; Iezzoni and Pritts, 1991). The knowledge gaps concerning the nature of relationships between fruit quality and the above-mentioned factors entail performing research on fruit quality variability without any sophisticated a priori model. Thus, this type of study falls into the field of exploratory research, of which the main aim is to select among the numerous biological hypotheses, those which can afterwards be experimentally tested or used for modelling.

The scope of this study was to search for within tree factors governing fruit quality variation. The components of fruit quality studied were colour, firmness and flavour. The factors hypothesized to control quality variation were linked with fruit position, microclimate (light), production of assimilates (leaf area), translocation of assimilates (characteristics of shoots) and use of assimilates by fruit (yield). We described the between-fruit variation of the quality and searched for factors governing quality variation using a multivariate exploratory approach. We synthesized our results in a semantic model of quality elaboration.

\section{MATERIAL AND METHODS}

The fruits were grown on 12 8-year-old peach trees planted in the orchard of the INRA Avignon centre. The cultivar used was the late maturing 'Suncrest'/GF 677. Trees were goblet trained and received routine horticultural care. In order to simplify the system under study, the analysis was limited to the southern part of each tree. In April 1989, four shoots per tree and $80 \%$ of 
the fruit of each shoot were randomly sampled. Only 101 fruits could be harvested because of high fruit drop in spring. So two to three fruit per shoot (seven to eleven per tree) were sampled. This is approximately $10 \%$ of the total fruits of the south part of the trees. Fruits were harvested at the end of July and the first part of August 1989 when ripe: fruit diameter increase had stopped, the fruits were softening, had a yellow ground colour and were easily picked.

A computer vision system was used to estimate the percentage of yellow, orange, red and purple on the fruit surface. The fruit overcolour was measured using a tristimulus colourimeter in 'Commission Internationale d'Eclairage' (CIE) L* $a^{*} b^{*}$ Colour Space coordinates (Hunter, 1975). In this system, $\mathrm{L}^{*}$ represents the value (lightness) of colours; it is low for dark colours and high for light colours; $\mathrm{a}^{*}$ is negative for green and positive for red, whereas $b^{*}$ is negative for blue and positive for yellow.

Flesh firmness $\left(\mathrm{kg} \mathrm{cm}^{-2}\right)$ was measured on the blush side of each fruit and on the opposite side with a penetrometer fitted with a $6 \mathrm{~mm}$ diameter probe.

Flavour quality was measured by concentration of soluble solids which is well correlated to sensory evaluation (Crochon, 1985), and by the sugars and acids. Sucrose is the main sugar of peach fruit, the others being reducing sugars, such as glucose and fructose (Souty and André, 1975; Bassi and Selli, 1990). Citric and malic acids are the main acids in 'Suncrest' (Bassi and Selli, 1990). The concentration of soluble solids ( $\mathrm{g}$ per $100 \mathrm{~g}$ fresh weight) of the juice was measured using a hand-held Sopelem $0-30 \%$ refractometer. The concentrations ( $\mathrm{g}$ per $100 \mathrm{~g}$ fresh weight) of sucrose and reducing sugars were measured by the cupric-neocuproine method (Bittner and Manning, 1967). Citric and malic acids (meq per $100 \mathrm{~g}$ fresh weight) were measured by enzymatic dosage (Moellering and Gruber, 1966; Möllering, 1974). The $\mathrm{pH}$ of the juice was also measured.

Fruit position in the tree was described by its above ground height and its position on the bearing shoot. The latter position was measured by the distance between the insertion of the shoot on the limb and the insertion of the fruit on the shoot. This distance was expressed in $\mathrm{cm}$ (D1) or in percentage of the shoot length (D2). The microclimatic measurements were limited to the exposure of the fruit to light. The percentage of light on the fruit skin was estimated visually, based on reference figures. Measurements were made before harvest during a sunny day at $7,8,9,10,12,14,15,16$ and 17 solar h. These data were reduced to variables, being a linear combination of the original variables, using a Principal Component Analysis (PCA). The goal of the PCA is to summarize a multivariate dataset as accurately as possible using a reduced number of uncorrelated components. The successive components summarize a decreasing part of data variance (Lebart et al., 1984). The total leaf area of the shoot and the leaf area per fruit were chosen as descriptors of the assimilate production by the shoot. The number of leaves was recorded 
each week from 28 April to the beginning of harvest and leaf areas were estimated using a linear relationship between leaf number and leaf area established on a sample $\left(r=0.99 ; P<10^{-4}\right)$. The successive measurements of total leaf area, along with those of leaf area per fruit, were highly inter-correlated. To prevent bias in the analysis, we selected only weeks with measurements weakly correlated to each other. Thus, total leaf areas at 28 April, 25 May and at the beginning of harvest (26 July) were used. Leaf areas per fruit at the same dates and 14 June were used. The characteristics of shoots which account for assimilate transport like shoot diameter, shoot length and shoot tilting were measured in the Spring, when the fruit were small. Two variables linked with the use of assimilates, total fresh yield and mean fresh weight per shoot, were measured at harvest. The list of the variables used, their abbreviated names and units are presented in Table 1.

The variability of both quality and explanatory variables was described using coefficients of variation. Some quality and explanatory variables were transformed to reduce skewness distribution using square root or logarithm transformations. Then, correlations between quality variables were calculated to identify sets of correlated variables. The quality variables were standardized to eliminate bias in multivariate analysis as a result of the different magnitudes of the units of measurement used. The set of quality variables (data Table Y) was explained by the set of explanatory variables (data Table $\mathrm{X}$ ) using a Principal Component Analysis with Instrumental Variables (PCAIV) (Sabatier et al., 1989). PCAIV proceeds in two steps. First, it performs the $p$ simultaneous multiple regression of the $p$ variables of $Y$ on the $q$ variables of $X$. These regressions are used to calculate the best linear approximation of $Y$. This approximation of $Y$ forms a new data table $\left(Y_{\mathrm{m}}\right)$ which represents the part of the quality explained by the explanatory factors (position, leaf area, light, etc.). We named the variables of $Y_{\mathrm{m}}$ 'modeled' variables because they come from the above linear model. Secondly, $Y_{\mathrm{m}}$ is analysed using PCA.

The interpretation of the PCAIV was based on different numerical criteria and graphics. We calculated the ratio $I=$ inertia of $Y_{\mathrm{m}}$ : inertia of $Y$, which is the estimated part of the variance of the original data explained by the explanatory variables. A randomisation test was used to test the significance of $I$ (Noreen, 1989). This procedure consisted in shuffling the rows of matrix $Y$ relative to the fixed matrix of explanatory variables $X$ and computing the 'random' ratio $I_{0}$. This procedure was repeated 1000 times. Comparing $I$ with the simulated distribution of $I_{0}$ yielded the significance level of the test statistic under the null hypothesis that $Y$ is unrelated to $X$. To test the significance of the observed inertia taken into account by $k$ PCA components, a randomisation test was also performed. Shuffling the rows of the columns of $Y_{\mathrm{m}}$ independently from each other and computing the inertia of the first $k$ components was repeated 1000 times. The observed inertia was compared with the 


\section{TABLE 1}

Abbreviated names, mean, range and coefficient of variation of quality and explanatory variables (not transformed to reduce skewness)

\begin{tabular}{|c|c|c|c|c|c|}
\hline & \multirow{2}{*}{$\begin{array}{l}\text { Abbreviated } \\
\text { name }\end{array}$} & \multirow[t]{2}{*}{ Mean } & \multicolumn{2}{|l|}{ Range } & \multirow{2}{*}{$\begin{array}{l}\text { Coefficien } \\
\text { of } \\
\text { variation }\end{array}$} \\
\hline & & & $\min$ & $\max$ & \\
\hline \multicolumn{6}{|l|}{ Quality variables } \\
\hline $\mathrm{L}^{*}$ & $\mathrm{~L}^{*}$ & 38.0 & 31.9 & 45.9 & 7.0 \\
\hline$a^{*}$ & $a^{*}$ & 13.0 & 0.1 & 26.3 & 46.2 \\
\hline$b^{*}$ & $b^{*}$ & 11.6 & 2.8 & 20.3 & 36.8 \\
\hline Yellow (\%) & Yel & 2.7 & 0.7 & 21.6 & 103.8 \\
\hline Orange $(\%)$ & Ora & 15.5 & 3.5 & 35.9 & 41.4 \\
\hline $\operatorname{Red}(\%)$ & Red & 55.2 & 39.4 & 68.6 & 11.3 \\
\hline Purple (\%) & Pur & 26.6 & 11.2 & 51.1 & 35.0 \\
\hline $\begin{array}{l}\text { Firmness on the blush side of } \\
\text { the fruit }\left(\mathrm{kg} \mathrm{cm}^{-2}\right)\end{array}$ & Fib & 0.3 & 0.1 & 4.0 & 145.0 \\
\hline $\begin{array}{l}\text { Firmness on the uncoloured } \\
\text { side of the fruit }\left(\mathrm{kg} \mathrm{cm}^{-2}\right)\end{array}$ & Fiu & 0.3 & 0.1 & 4.7 & 147.5 \\
\hline Soluble solids ( $\mathrm{g}$ per $100 \mathrm{~g}$ ) & Ss & 10.4 & 7.2 & 18.2 & 23.2 \\
\hline Sucrose $(\mathrm{g}$ per $100 \mathrm{~g}$ ) & Suc & 5.2 & 1.2 & 12.0 & 54.2 \\
\hline Reducing sugars (g per $100 \mathrm{~g}$ ) & Rs & 2.6 & 1.5 & 4.3 & 19.6 \\
\hline Citric acid (meq per $100 \mathrm{~g}$ ) & Cit & 3.2 & 0.0 & 12.6 & 79.6 \\
\hline Malic acid (meq per $100 \mathrm{~g}$ ) & Mal & 6.3 & 1.8 & 14.7 & 39.2 \\
\hline $\mathrm{pH}$ & $\mathrm{pH}$ & 4.0 & 3.7 & 4.2 & 2.8 \\
\hline \multicolumn{6}{|l|}{ Explanatory variables } \\
\hline Fruit Height $(\mathrm{cm})$ & Hei & 182.9 & 114.0 & 240.0 & 18.1 \\
\hline Fruit position on shoot $(\mathrm{cm})$ & D1 & 59.8 & 6.0 & 126.0 & 42.1 \\
\hline Fruit position on shoot $(\%)$ & D2 & 70.0 & 30.0 & 100.0 & 29.6 \\
\hline \multicolumn{6}{|l|}{ Fruit exposure (\%) } \\
\hline $7 \mathrm{~h}$ & & 10.0 & 0.0 & 60.0 & 142.7 \\
\hline $8 \mathrm{~h}$ & & 13.0 & 0.0 & 50.0 & 114.3 \\
\hline $9 \mathrm{~h}$ & & 17.0 & 0.0 & 60.0 & 97.5 \\
\hline $10 \mathrm{~h}$ & & 18.0 & 0.0 & 60.0 & 93.9 \\
\hline $12 \mathrm{~h}$ & & 28.0 & 0.0 & 70.0 & 63.6 \\
\hline $14 \mathrm{~h}$ & & 25.0 & 0.0 & 60.0 & 70.4 \\
\hline $15 \mathrm{~h}$ & & 22.0 & 0.0 & 60.0 & 71.2 \\
\hline $16 \mathrm{~h}$ & & 15.0 & 0.0 & 50.0 & 107.5 \\
\hline $17 \mathrm{~h}$ & & 8.0 & 0.0 & 50.0 & 154.7 \\
\hline \multicolumn{6}{|l|}{ Total leaf area $\left(\mathrm{cm}^{2}\right)$} \\
\hline 28 April & $\mathrm{A} 1$ & 820.0 & 220.0 & 1196.0 & 31,6 \\
\hline 25 May & $\mathrm{A} 2$ & 1695.0 & 368.0 & 2647.0 & 34.4 \\
\hline 26 July & $\mathrm{A} 3$ & 5472.0 & 919.0 & 13371.0 & 64.6 \\
\hline \multicolumn{6}{|l|}{ Leaf area per fruit $\left(\mathrm{cm}^{2}\right)$} \\
\hline 28 April & Afl & 155.0 & 82,0 & 343.0 & 47.0 \\
\hline 25 May & Af2 & 354.0 & 175.0 & 762.0 & 37.5 \\
\hline 14 June & Af3 & 700.0 & 272.0 & 1876.0 & 44.6 \\
\hline 26 July & Af4 & 1412.0 & 437.0 & 4019.0 & 60.0 \\
\hline
\end{tabular}




\begin{tabular}{|c|c|c|c|c|c|}
\hline & \multirow{2}{*}{$\begin{array}{l}\text { Abbreviated } \\
\text { name }\end{array}$} & \multirow[t]{2}{*}{ Mean } & \multicolumn{2}{|l|}{ Range } & \multirow{2}{*}{$\begin{array}{l}\text { Coefficient } \\
\text { of } \\
\text { variation }\end{array}$} \\
\hline & & & $\min$ & $\max$ & \\
\hline Shoot diameter (mm) & Dia & 11.8 & 6.4 & 18.2 & 23.6 \\
\hline Shoot length $(\mathrm{cm})$ & Len & 80.2 & 25.0 & 120.0 & 28.4 \\
\hline Shoot tilting $\left({ }^{\circ}\right)$ & Til & -13.0 & -59.0 & 49.0 & 199.0 \\
\hline Yield of fruit $(\mathrm{g})$ by shoot & Yie & 347.5 & 45.0 & 712.0 & 49.7 \\
\hline Mean fruit weight $(\mathrm{g})$ & Wei & 84.4 & 33.2 & 126.6 & 22.6 \\
\hline
\end{tabular}

simulated distribution of inertia and provided the significance level of the test statistic under the null hypothesis that observed inertia is random.

The solution of PCAIV is displayed in diagrams. The PCAIV scores of fruit were plotted on PCAIV axes. The correlations of the modeled quality variables and of explanatory variables, with the highest inertia components, were plotted on diagrams named 'correlation plots'. Variables are displayed by means of vectors whose coordinates are correlations with components. Thus, the cosines of angles between vectors are equivalent to correlations. The vectors with lengths close to one are well correlated with the plane of the two components and are the most important for the interpretation of the plane.

\section{RESULTS}

The between-fruit variation of the quality variables was high, except $\mathrm{L}^{*}$, red colour, and $\mathrm{pH}$ (Table 1 ). Similarly, the variability of the explanatory variables was high (Table 1). For example, the shoot diameter ranged from 6 to $18 \mathrm{~mm}$ and leaf area by shoot in July ranged from $900 \mathrm{~cm}^{2}$ to $13000 \mathrm{~cm}^{2}$.

$\mathrm{L}^{*}, \mathrm{a}^{*} \mathrm{~b}^{*}$, yellow and orange colour variables were positively correlated to each other and were negatively correlated to purple colour (Table 2). Thus, the fruit could be ordered along a colour gradient from luminous yelloworange fruits to dark purple fruits. Among colour variables, only yellow was well correlated with the set of flavour and firmness variables (Table 2). Among flavour variables, soluble solids were highly correlated to sucrose because sucrose is the main compound of soluble solids. Thus, the soluble solids variable was removed from subsequent analysis. Citric acid and firmness were positively correlated to each other and negatively correlated with sucrose (Table 2 ). The gradient constructed by these variables was interpreted as an opposition between firm sour and soft sweet fruits, because sucrose was the dominant sugar, and citric acid gave a sourer taste than other acids in peach fruits. The reducing sugars, malic acid and $\mathrm{pH}$ were only partly related to this gradient (Table 2). Thus, the quality variables were grouped into three sets, which corresponded respectively to the colour gradient, sweet-sour and firmness gradient and to the other variables. 


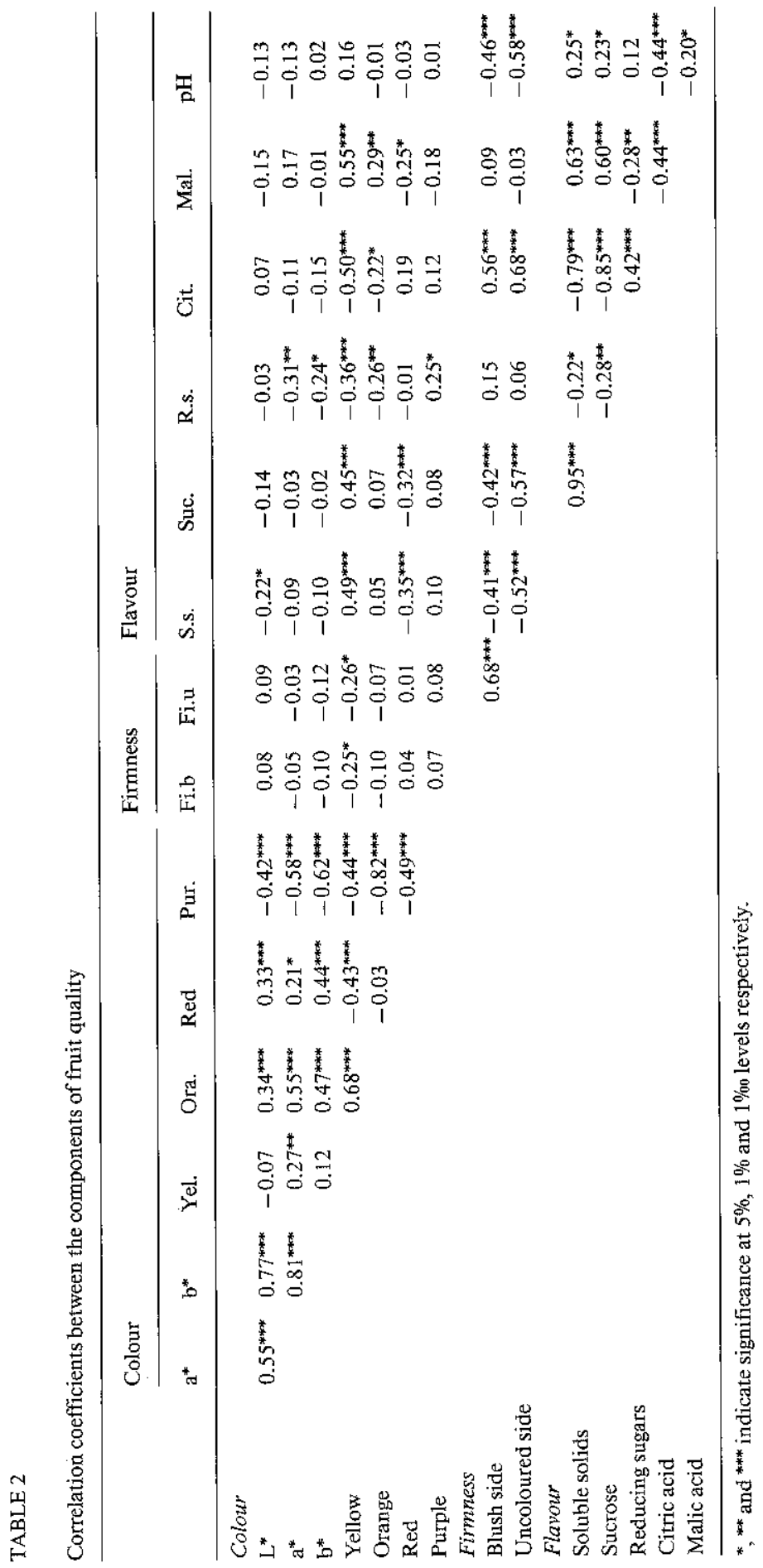



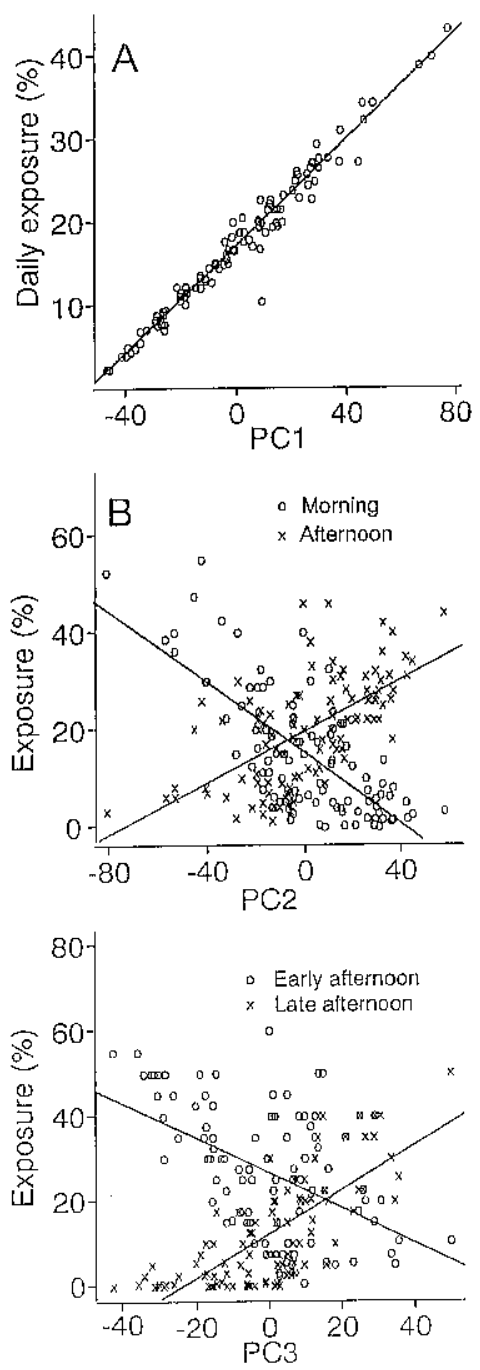

Fig. 1. Relationships between PCA components and fruit exposure: mean daily exposure of fruit * first component (A); mean exposure in the morning and in the afternoon * second component (B); mean exposure during early afternoon and during late afternoon * third component (C). Regression lines are fitted by least squares procedure.

The first three components of the PCA on exposure measurements, which accounted for $72.3 \%$ of the variance of the original data set, were selected. The first component (Light 1) was interpreted as a gradient of increasing mean daily exposure of the fruit to light (Fig. 1). The second component (Light 2) opposed fruits more sunlit in the morning (negative values) to those sunlit in the afternoon (positive values; Fig. 1). The third component (Light 

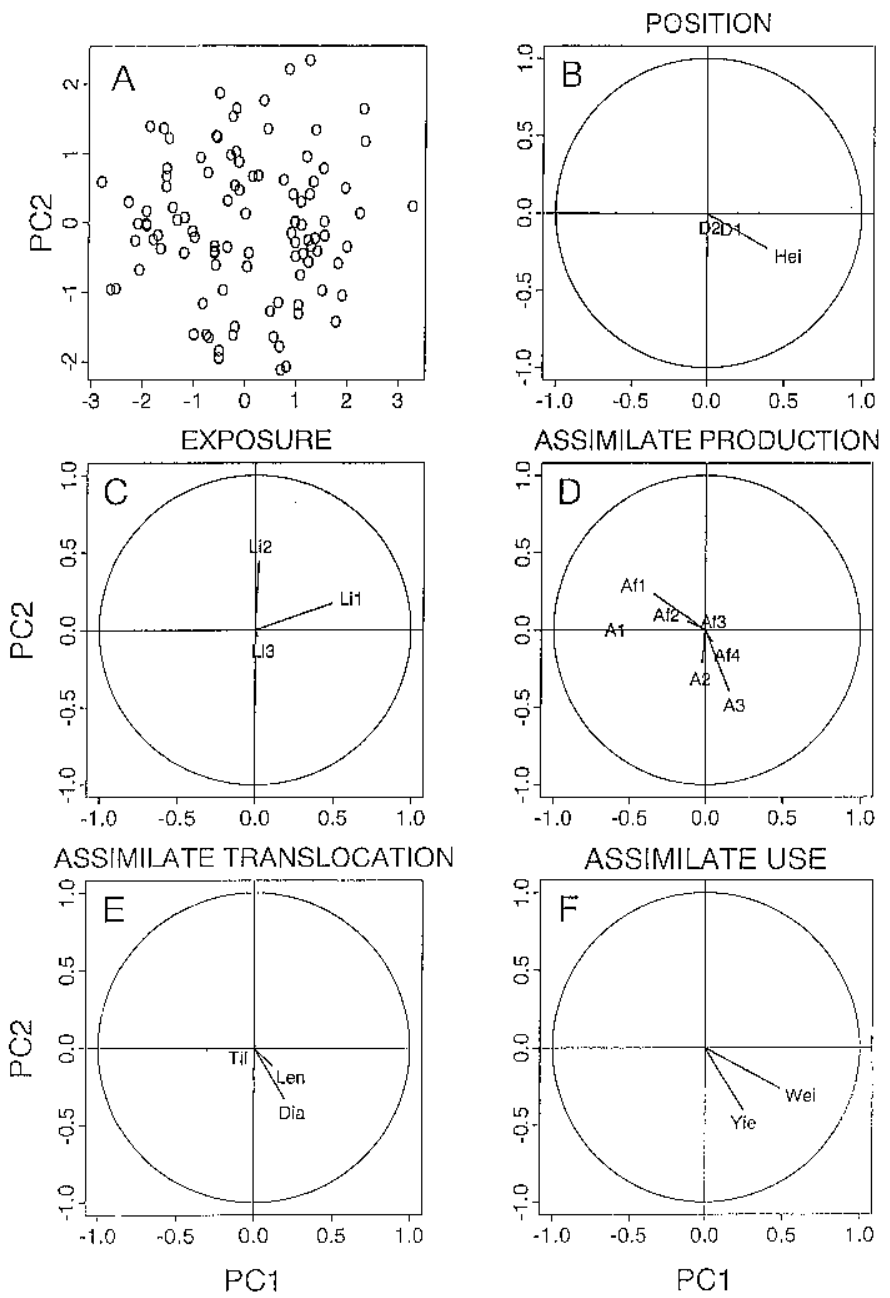

Fig. 2. PCAIV scores of fruits (A) and correlation plots of explanatory variables $(B-F)$ for the first two components. The circle is 1 -radius. Li1 $=$ Light $1 ; \mathrm{Li} 2=$ Light $2 ; \mathrm{Li} 3=\mathrm{Light} 3$.

3 ) opposed fruits more sunlit in the early afternoon (negative values) to those sunlit in the late afternoon (positive values; Fig. 1).

The explanatory factors accounted for $I=30 \%$ of the variance of the quality variables at a significance level of 0.001 . The first plane PC1*PC2 of the PCAIV, which accounted for $66 \%$ of the inertia at a significance level of 0.001 , was interpreted. The fruits are uniformly distributed on the PC1*PC2 plane (Fig. 2). Hence, it seems there are no clearly differenciated groups of fruit quality, but a gradual variation of quality within the studied population. The modeled colour, firmness and flavour variables were well correlated with the subspace of the two components (the vectors have a length close to 1; Fig. 3 ). 
QUALITY

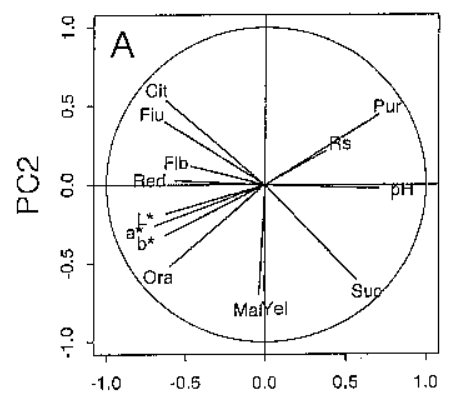

SWEET-SOUR and FIRMNESS GRADIENT

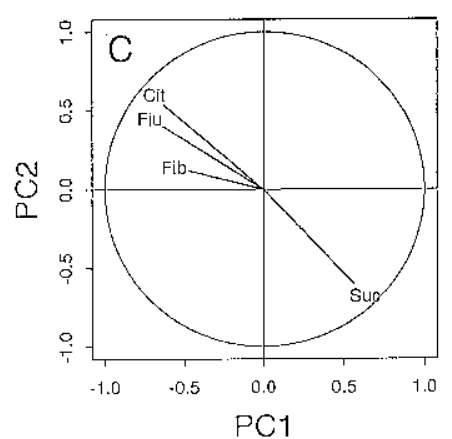

COLOÜR GRADIENT

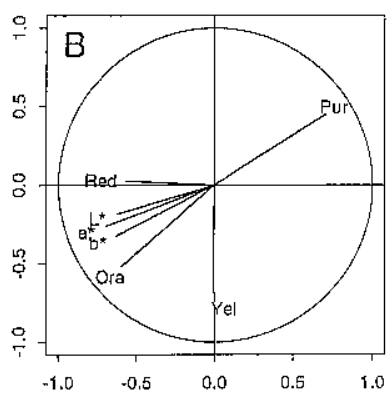

Other flavour variables

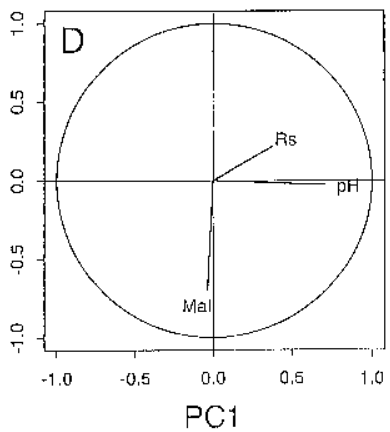

Fig. 3. Correlation plots of quality variables ( $A$, all variables; $B-D$, by group) for the first two PCAIV components. The circle is 1 -radius.

Correlations between the modeled quality variables displayed on the $\mathrm{PC} 1{ }^{*} \mathrm{PC} 2$ factor plane were similar to the above-mentioned correlation between quality variables. The relationships between the quality and explanatory variables are presented using the $\mathrm{PC1}$ *PC2 plane (Figs. 2 and 3 ).

The height of the fruit in the tree was the only position variable related to the $\mathrm{PC} 1{ }^{*} \mathrm{PC} 2$ plane. This variable was related to the colour gradient as well as to the firmness and sweet-sour gradient. Thus, fruits in the upper parts of the tree were more purple, less orange-red, less firm, had a higher sucrose content, weaker citric acid content and higher $\mathrm{pH}$ than fruits in the lower parts.

As for fruit exposure, Light 1 and Light 2 were related to $\mathrm{PC} 1{ }^{*} \mathrm{PC} 2$ plane. Fruits well exposed during the day (Light 1 ) had a purple skin, whereas fruits less exposed were more orange-red and had a higher luminance $\left(\mathrm{L}^{*}\right)$ and chrominance $\left(\mathrm{a}^{*}, \mathrm{~b}^{*}\right)$. Well exposed fruits also had the greatest amount of 
reducing sugar and high $\mathrm{pH}$. Fruits essentially exposed to light in the afternoon (Light 2) were more purple, less yellow and orange and had a higher firmness on the blush side of the fruit, a higher citric acid content, lower sucrose and malic acid contents than fruits exposed to light in the morning.

The two descriptors of assimilate production (total leaf area and leaf area per fruit) were related to the $\mathrm{PC} 1{ }^{*} \mathrm{PC} 2$ plane. The colour variables were generally not correlated with leaf area per fruit. Fruits linked with a high total leaf area early in season were more orange-red, less purple and had higher $L^{*}$, $a^{*}, b^{*}$ than other fruits. Fruits linked with a high total leaf area late in season were the yellowest. Firm sour fruits (high citric acid content, low pH and sucrose) were linked with high total leaf area and high leaf area per fruit early in season. Sweet fruits (high sucrose content) with a high malic acid content were linked with high total leaf area and high leaf area per fruit late in season.

Shoot diameter was the only descriptor linked with the transport of assimilates related to the PC1*PC2 plane. Fruits borne by thick shoots were sweeter and yellower and had a higher malic acid content than fruits borne by thin shoots. The two variables linked with assimilate use (fresh yield of fruit and mean weight of fruit) were related to the $\mathrm{PC} 1{ }^{*} \mathrm{PC} 2$ plane. The softest and sweetest fruits were on shoots with high fruit yield, where fruits had a high mean weight. Yellow and malic acid were positively correlated to yield and $\mathrm{pH}$ was positively correlated to mean weight of fruit.

\section{DISCUSSION}

The between-fruit variation of the quality variables for the studied cultivar was as large as the between-cultivar variation studied by Souty and André (1975), Delwiche and Baumgardner (1983) and Bassi and Selli (1990). The correlations between quality variables made it possible to describe both a colour gradient and a sweet-sour and firmness gradient in the studied sample. A high negative correlation between sucrose and citric acid was noted, along with a positive correlation between firmness and citric acid. Citric acid possibly affects sucrose hydrolysis as has been noted for Acid Lime (Echeverria and Burns, 1990) and high acidity could inhibit enzymes responsible for the decrease of firmness (Romani and Jennings, 1971). But the work of Brown and Walker (1990) and research in progress show that different relationships between quality variables can be obtained with different cultivars or species.

Contrary to what was shown in the cherry (Patten et al., 1986), no relationship was found between colour and the position of the fruit on the shoot. However, as noted by Marini (1985) the blush part of the peach skin increased with height. This effect of height seems to be independent of the light received by the fruit late in season, since height and exposure were not significantly correlated $(r=-0.16, P=0.11)$.

Light is one of the main factors responsible for anthocyanin synthesis in 
fruit skin (Erez and Flore, 1986) and thus fruit colour (Marini et al., 1991). Thus, it was noted that fruits, well sunlit late in the season, were more purple. Though exposure early in the season was not measured, it is possible that a low fruit exposure on shoots with a high leaf area early in the season could explain their less purple colour. In the same way, the increase of yellow when leaf area increases late in season might be due to a higher number of leaves pasted on the fruit, which protect the skin from sunlight. The time of day during which the fruit is sunlit may also affect colour. However, we are unaware of similar reports in literature. The relationships between yellow colour and the shoot diameter as well as between yellow colour and yield could be due to high correlations between these variables and leaf area in late season $(r=0.84$ and 0.69$)$.

Hereafter, the results concerning the sweet-sour gradient are discussed in comparison with results in literature. These concern, notably, soluble solids. In fact, the results obtained show that soluble solids are clearly linked to this gradient. Contrary to the results obtained for cherries (Patten et al., 1986), no difference was found in the sweet-sour balance according to the location of the fruits on the shoot. As also noted for the peach (Marini, 1985; Dann and Jerie, 1988) the sweetest and softest fruits were in the highest part of the studied trees. This relationship may account for a direct effect of position through hormonal signals (Chalmers, 1986). It may be also an indirect effect, because leaves at the top of trees receive more light than those at the bottom and because light is the primary resource for photosynthesis. Thus, fruits located low in the tree may be disadvantaged by low assimilate supplies. Hence, these fruits may have a lower sugar content, and would be the sourest fruits.

Daily exposure of the fruit itself was not correlated to the sweet-sour and firmness gradient, which concurs with the results of Marini et al. (1991). However, reducing sugars and $\mathrm{pH}$ increased with exposure and the fruits essentially exposed to sun in the afternoon had low sucrose and malic acid levels as well as high levels of citric acid and high firmness. These relationships between carbohydrates, organic acids, firmness and exposure might be due to an effect of light on production of many plant hormones (Letham et al., 1978) or on the fruit temperature. Indeed, fruit highly exposed to sun on warm summer afternoons were probably subject to high temperatures. This could inhibit enzymes, such as sucrose synthetase, which acts on sucrose production within the tree (Moriguchi et al., 1990) or pectinase, which acts on firmness.

The sweetest fruits with high malic acid content were situated on shoots with a high assimilate use and a high potential of assimilate production (high total leaf area and leaf area per fruit) late in season, i.e. during rapid increase of fruit growth. Numerous works concerning ringed branches on peach trees (Weinberger, 1931; Jones, 1932) agree with these results, but they present better relationships than ours. When branches are not ringed the relationship may disappear, as in the cherry (Facteau et al., 1983). In studies on ringed 
branches, the cause of the good observed relationships is the increasing assimilate production with the increasing leaf area on the branch. In studies such as ours concerning non-ringed branches, assimilates could also be supplied by leaves from other branches or by reserves through long distance transport of assimilates (Roper et al., 1987). The positive relationship between sucrose content and shoot diameter, the latter being able to improve the transport of assimilates, is coherent with this hypothesis. Another hypothesis is that the rate of leaf photosynthesis increases when leaf area per fruit decreases (Dejong, 1986). According to these two hypotheses, the assimilate supply of fruits on poorly foliated shoots could be higher than predicted by leaf area alone. This would diminish the relationship between the sweet-sour gradient and leaf area. The negative relationship between sucrose and leaf area per fruit early in the season might be due to competition between leaf expansion and fruit growth.

Only a relatively small part of the quality variability has been explained. This may be due namely to the overlooking of significant explanatory variables, such as bloom time (Patten et al., 1986) and to complex relationships between components of quality and explanatory factors. For example, Marini et al. (1991) showed that peach fruit coloration depends on a succession of shaded and sunlit periods, which could explain the relatively poor relationships between colour and exposure.

There are three main horticultural implications of this work. Firstly, the between-fruit variation of the quality is large, which shows that tree manage-

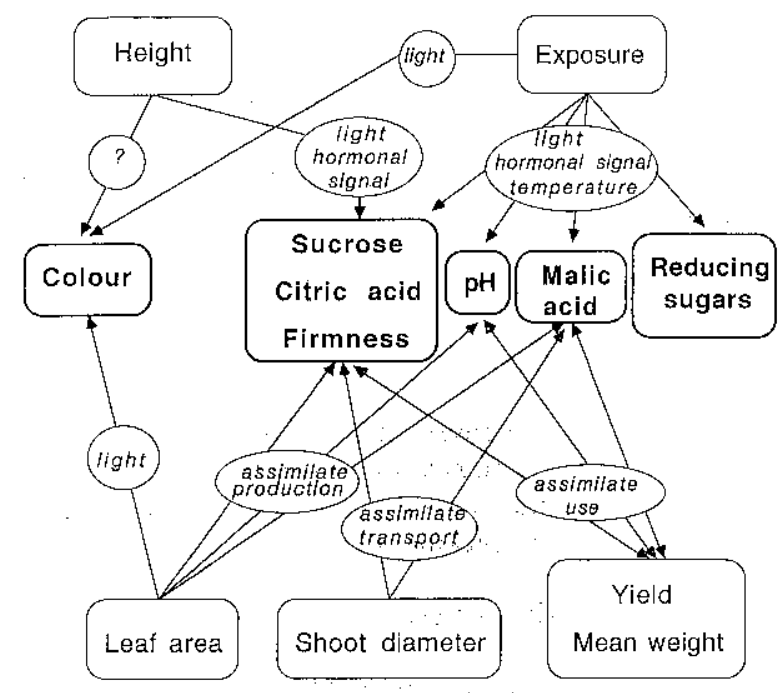

Fig. 4. Semantic model of quality elaboration. States are represented in boxes and proposed processes in circles. Single arrows indicate causal relationships and double arrows indicate interrelations. 
ment can probably still be improved. Secondly, the variation of colour is almost independent of that of the biochemical composition and firmness of peach fruit. Thus, it seems difficult to manage trees for both good gustatory quality and high coloration. Thirdly, this study has shown that quality components are determined by a number of factors. A semantic model of quality elaboration is proposed as a function of these factors, which could be used in order to develop a statistical model for the prediction of fruit quality (Fig. 4). In this semantic model, the height of fruit within the tree and shoot diameter only affect some quality components, whereas exposure, leaf area and yield affect most quality components. The processes supposed to affect fruit quality are essentially the supply of assimilates and their use. There is also the light effect, since light affects assimilate supply by enhancing photosynthesis and affects fruit metabolism and colour. Research is needed to test our results in other situations and to improve the proposed schema, which pertains only to fruit of the south side of the tree.

\section{ACKNOWLEDGEMENTS}

We would like to thank $F$. Lescourret and L. Pagès for helpful comments on this paper, M. Souty, L. Breuils and M. Reich for technical assistance. The 'Région PACA' is also thanked for partially funding this project (contracts number $90 / 03399,90 / 03400$ and $91 / 0541600)$.

\section{REFERENCES}

Bassi, D. and Selli, R., 1990. Evaluation of fruit quality in peach and apricot. Adv. Hort. Sci., 4: $107-112$.

Bittner, D.L. and Manning, J., 1967. Automated neocuproïne glucose method: critical factors and normal values. Automation in Analytical Chemistry, Technicon corp, Mediad, New York, pp. 33-36.

Broschat, T.K., 1979. Principal Component Analysis in horticultural research. HortScience, 14: 114-117.

Brown, G.S. and Walker, T.D., 1990. Indicators of maturity in apricots using biplot multivariate analysis. J. Sci. Food Agric., 53: 321-331.

Chalmers, D.J., 1986. Position as a factor in growth and development effects. In: R.P. Pharis and D.M. Reids (Editors), Interrelationships of Hormones with Factors in Environment. Encyclopedia Physiology New Series, Springer, Berlin, pp. 169-192.

Crochon, M., 1985. Quality of peaches as a function of picking time and consumer's preferences. Acta Horticulturae, 173: 433-440.

Dann, I.R. and Jerie, P.H., 1988. Gradients in maturity and sugar level of fruit within peach trees. J. Am. Soc. Hortic. Sci., 113: 27-31.

Dejong, T.M., 1986. Fruit effect on photosynthesis in Prunus persica. Physiol. Plant., 66: 149153.

Delwiche, M.J. and Baumgardner, R.A., 1983. Ground color measurements of peach. J. Am. Soc. Hortic. Sci., 108: 1012-1016. 
Echeverria, E. and Burns, J.K., 1990. Sucrose breakdown in relation to fruit growth of acid lime (Citrus aurantifolia ). J. Exp. Bot., 41: 705-708.

Erez, A. and Flore, J.A., 1986. The quantitative effect of solar radiation on "Redhaven" peach fruit skin color. HortScience, 21: 1424-1426.

Facteau, T.J., Chestnut, N.E. and Rowe, K.E., 1983. Relationship between fruit weight, firmness, and leaf/fruit ratio in Lambert and Bing sweet cherries. Can. J. Plant. Sci., 63: 763765.

Génard, M., Bruchou, C. and Souty, M., 1991. Relation entre croissance et qualité chez la pêche. In: J.L. Poëssel and F. Bergougnoux (Editors), Ninth Colloque sur les Recherches Fruitières, 4-6 December 1990, CTIFL-INRA, Avignon, France, pp. 123-134.

Hunter, R.S. (Editor), 1975. The measurement of appearance. Wiley-Interscience, New York, $348 \mathrm{pp}$.

Iezzoni, A.F. and Pritts, M.P., 1991. Application of Principal Component Analysis to horticultural research. HortScience, 26: 334-338.

Jones, I.D., 1932. Further observations on influence of leaf area on fruit growth and quality in Peach. Proc. Am. Soc. Hortic. Sci., 29: 34-38.

Lebart, L., Morineau, A. and Warwick, K.M. (Editors), 1984. Multivariate descriptive statistical analysis. Correspondence analysis and related techniques for large matrices. John Wiley \& Sons, New York, $231 \mathrm{pp}$.

Letham, D.S., Goodwin, P.B. and Higgins, T.J.V. (Editors), 1978. Phytohormones and related compounds: a comprehensive treatise, Vol. II. Elsevier, Amsterdam, 641 pp.

Marini, R.P., 1985. Vegetative growth, yield, and fruit quality of peach as influenced by dormant pruning, summer pruning, and summer topping. J. Am. Soc. Hort. Sci., 110: 133-139.

Marini, R.P., Sowers, D. and Marini, M.C., 1991. Peach fruit quality is affected by shade during final swell of fruit growth. J. Am. Soc. Hortic. Sci., 116: 383-389.

Moellering, H. and Gruber, W., 1966. Determination of citrate with citrate lyase. Anal. Biochem., $17: 369-376$.

Möllering, H., 1974. Determination with malate dehydrogenase and glutamate-oxaloacetate transaminase. In: H.U. Bergmeyer (Editor), Methods of Enzymatic Analysis, Vol. 3. Verlag Chemie Weinheim, Academic Press, New York, pp. 1589-1593.

Moriguchi, T., Sanada, T. and Yamaki, S., 1990. Seasonal fluctuations of some enzymes relating to sucrose and sorbitol metabolism in peach fruit. J. Am. Soc. Hortic. Sci, 115: 278-281.

Noreen, E.W. (Editor), 1989. Computer-intensive methods for testing hypotheses: an introduction. John Wiley \& Sons, New York, 229 pp.

Patten, K.D., Patterson, M.E. and Proebsting, E.L., 1986. Factors accounting for the withintree variation of fruit quality in sweet cherries. HortScience, $21: 356-360$.

Romani, R.J. and Jennings, W.G., 1971. Stone fruits. In: A.C. Hulme (Editor), The Biochemistry of Fruits and Their Products. Vol. 2. Academic Press, London, 788 pp.

Roper, R., Loescher, W.H., Keller, J. and Rom, C.R., 1987. Sources of photosynthate for fruit growth in "Bing" sweet cherry. J. Am. Soc. Hortic. Sci., 112: 808-812.

Sabatier, R., Lebreton, J.D. and Chessel, D., 1989. Principal component analysis with instrumental variables as a tool for modelling composition data. In: R. Coppi and S. Bolasco (Editors). Multiway Data Analysis. Elsevier, Amsterdam, pp. 341-352.

Souty, M. and André, P., 1975. Composition biochimique et qualité des pêches. Ann. Technol. Agric., 24: 217-236.

Weinberger, J.H., 1931. The relation of leaf area to size and quality of peaches. Proc. Am. Soc. Hortic. Sci., 28: 18-22. 
$\therefore$
$\therefore$ 